\section{Lack of effect of propranolol and metoprolol on glucose tolerance in maturity-onset diabetics}

Although the effect of beta-blocking drugs on the response to hypoglycaemia has been extensively studied, less attention has been paid to the possibility that they might cause deterioration of glucose tolerance. Release of insulin is stimulated by beta-agonists, and two studies have shown that infusion of propranolol reduces insulin response to a glucose load in normal subjects. ${ }^{12}$ A group of maturity-onset diabetics tended to have higher blood sugars during chronic treatment with propranolol or the beta-selective agent metoprolol than when receiving placebo. ${ }^{3}$ We report here a controlled study of the effects of these two drugs at two dosage levels on the oral glucose tolerance and insulin response of a group of maturity-onset diabetics.

\section{Patients, methods, and results}

The patients were six hypertensive diabetics (mid-afternoon blood sugar $>10 \mathrm{mmol} / 1(180 \mathrm{mg} / 100 \mathrm{ml})$, phase IV diastolic blood pressure $>95 \mathrm{~mm}$ $\mathrm{Hg}$ on three occasions). None had previously received beta-blockers and all were in good general health. Four were receiving oral hypoglycaemic agents (metformin, tolazamide, tolbutamide, or chlorpropamide) and two diet alone. On five occasions at least one week apart each subject attended at 9 am after fasting and omitting any hypoglycaemic drugs for 12 hours beforehand. For two days before the study each received one of the following twice daily: placebo; metoprolol $100 \mathrm{mg}$; metoprolol $200 \mathrm{mg}$; propranolol $80 \mathrm{mg}$; propranolol $160 \mathrm{mg}$. Treatments were randomised between the five visits of each subject according to a double-blind cross-over protocol. On the morning of the study the final (fifth) dose was given with $100 \mathrm{ml}$ water, and one hour later $50 \mathrm{~g}$ glucose was given in $250 \mathrm{ml}$ water. Serial samples were taken for assay of plasma glucose, plasma potassium, and serum insulin concentrations.

Neither beta-blocker had a significant effect on fasting plasma glucose, glucose tolerance, or insulin response (figure). There was no suggestion of a dose-related trend falling short of statistical significance or of a consistent difference between propranolol and metoprolol. Potassium concentrations were consistently $0 \cdot 2-0 \cdot 3 \mathrm{mmol}(\mathrm{mEq}) / 1$ higher during beta-blockade than with placebo ( $\mathrm{p}<0.001$ by paired $t$ test), regardless of selectivity, and fell significantly during the three hours after glucose administration $(p<0.001)$ on all treatments, including placebo.

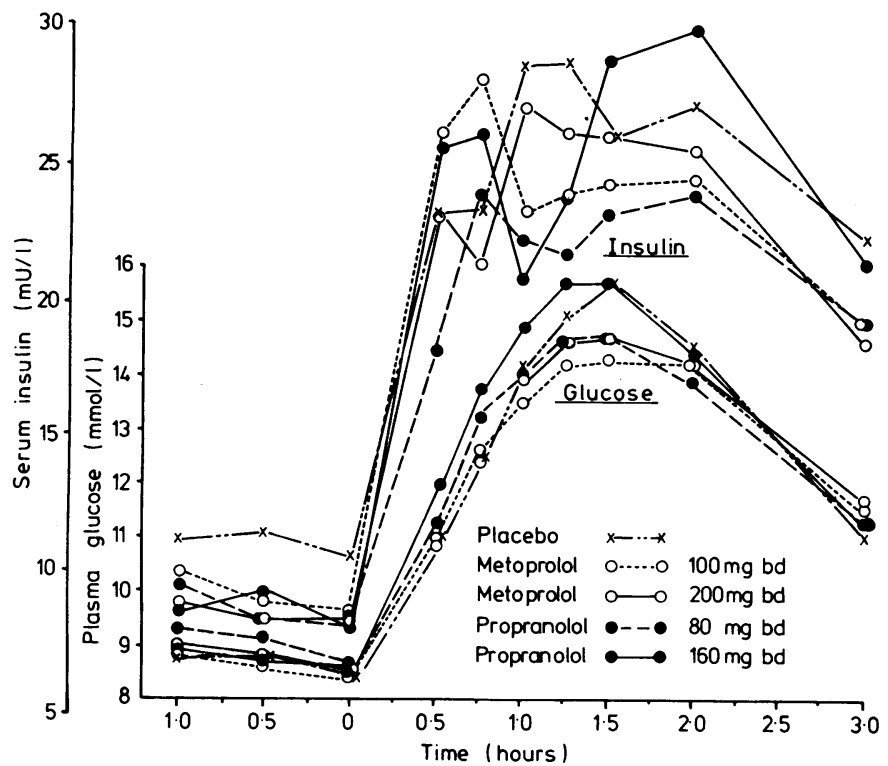

Insulin response and glucose tolerance after treatment with metoprolol, propranolol, or placebo. Glucose $50 \mathrm{~g}$ given orally at time 0 . Mean insulin values calculated from log-transformed raw data and shown detransformed. Conversion: SI to Traditional Units-Glucose: $1 \mathrm{mmol} / 1 \approx 18 \mathrm{mg} / 100 \mathrm{ml}$.

\section{Comment}

These results show that therapeutic doses of propranolol or metoprolol are unlikely to impair glucose tolerance in maturity-onset diabetics. We cannot, however, rule out the possibility that certain people respond idiosyncratically to beta-blockade, as has been reported occasionally. ${ }^{4}$ There is some evidence that a selective beta 1 -blocker has less effect on the response to hypoglycaemia and is therefore preferable. ${ }^{5}$ The small rise in plasma potassium during beta-blockade probably reflects a slight net shift of potassium from the intracellular compartment which is not usually of clinical significance.

We thank Mrs R Gibson and Mrs D Bradley for their help with these studies, and Astra Pharmaceuticals for financial support and supply of coded tablets.

${ }^{1}$ Cerasi E, Luft R, Efendic S. Effects of adrenergic blocking agents on insulin response to glucose infusion in man. Acta Endocrinol (Kbh) 1972;69:335-46.

${ }^{2}$ Myers MG, Hope-Gill HF. The effect of d- and dl-propranolol on glucose-stimulated insulin release. Clin Pharmacol Ther 1979 ;25:303-8.

${ }^{3}$ Wright AD, Barber SG, Kendall MJ, Poole PH. Beta-adrenoceptor blocking drugs and blood sugar control in diabetes mellitus. $\mathrm{Br} \mathrm{Med} \mathcal{F}$ 1979 ;i :159-61.

4 Waal-Manning HJ. Metabolic effects of beta-adrenoceptor blockers. Drugs 1976;11, suppl 1: 121-6.

${ }^{5}$ Lager I, Blohmé G, Smith U. Effect of cardioselective and non-selective beta-blockade on the hypoglycaemic response in insulin-dependent diabetics. Lancet 1979 ; i :458-62.

(Accepted 9 September 1980)

Queen Elizabeth Hospital, The General Hospital, and the Department of Medicine, University of Birmingham, Birmingham B15 2TH

K L WOODS, MD, MRCP, lecturer in therapeutics and clinical pharmacology A D WRIGHT, FRCP, senior lecturer in medicine

M J KENDALL, MD, MRCP, senior lecturer in therapeutics and clinical pharmacology

ELIZABETH BLACK, BSC, research fellow

\section{Tampon-associated toxic shock syndrome}

The toxic-shock syndrome is a recently described condition characterised by sudden onset of fever, diarrhoea, erythematous rash, and shock. It is thought to be due to staphylococcal toxins and is associated with the use of tampons. ${ }^{1}$ The patient reported here is the first British case.

\section{Case report}

A previously healthy 16-year-old girl was admitted to our hospital in February 1980 with a two-day history of high fever, vomiting, and drowsiness. On the day of admission she had developed a rash and watery diarrhoea with incontinence. On examination she was shocked and stuporous with a temperature of $40^{\circ} \mathrm{C}$ and a generalised punctate erythematous rash. She had purulent conjunctivitis and her tongue was coated. Chest and abdominal examination were normal. She was menstruating, however, and had a foul vaginal discharge. A tampon (Tampax regular) was recovered from the vagina; subsequent inquiry suggested that the tampon had been in the vagina for three days.

Staphylococcus aureus was isolated from a high vaginal swab and from the tampon. The strain was resistant to penicillin and was phage type 29/52 (group 1). Blood cultures, throat swabs, and cerebrospinal fluid were all sterile, although the cerebrospinal fluid contained $36 \times 10^{6}$ lymphocytes 1 $\left(36 / \mathrm{mm}^{3}\right)$. The urine was sterile but contained $490 \times 10^{6}$ white cells $/ 1$ $\left(490 / \mathrm{mm}^{3}\right)$. There was a neutrophil leucocytosis; platelets were $40 \times 10^{9} / 1$ $\left(40000 / \mathrm{mm}^{3}\right)$. Creatine Kinase activity was $1900 \mathrm{IU} / 1$ (normal 25-170 IU/1), and aspartate aminotransferase activity was $203 \mathrm{IU} / 1$ (normal 3-35 IU/1). Blood urea concentration was $24.5 \mathrm{mmol} / 1(147 \mathrm{mg} / 100 \mathrm{ml})$.

She was resuscitated with intravenous fluids and given gentamicin, lincomycin, and cloxacillin. Her condition slowly improved, and the fever settled in 48 hours. She remained oliguric for seven days, and her blood urea concentration rose to $61 \mathrm{mmol} / 1$ (366 mg/100 ml) on conservative management before a diuresis occurred. Ten days after admission she developed a large left-sided pleural effusion and 2.51 of sterile, straw-coloured transudate was aspirated. The rash underwent desquamation on the trunk and peeled on the hands.

She made a full recovery and was discharged home after 18 days in hospital, when the chest radiograph and blood urea concentration were normal. She received flucloxacillin for a total of six weeks. The anti-streptolysin $\mathrm{O}$ titre in convalescence was $112 \mathrm{IU} / 1$. She was seen one month later, when she had had one further period, and she was perfectly well. 


\section{Comment}

The toxic shock syndrome was first reported in seven children in $1978^{2}$; in five of these Staphylococcus aureus was isolated from various sites. The occurrence of toxic shock syndrome in menstruating women was first reported in $1980^{3}$; since then 299 cases have been reported in the United States with 25 deaths. ${ }^{4}$ About $95^{\circ}$ of these cases have occurred in menstruating women, all of whom had been using tampons. Staphylococcus aureus has been isolated from vaginal swabs in more than $90 \%$ of cases; blood cultures are always sterile. Our patient had all the features of the toxic shock syndrome, and phage group 1 Staph aureus was isolated from her vagina and from the tampon she was using.

The occurrence of scarlatiniform rashes in staphylococcal infections is well known and many of the features of toxic shock syndrome occur in staphylococcal septicaemia; in toxic shock syndrome, however, the organisms have not been found in the blood stream. It has been postulated that staphylococci in the genital tract produce a toxin which causes the syndrome ${ }^{4}$; the nature of this toxin has yet to be elucidated. Because we saw her before the toxic shock syndrome had been associated with tampons, we did not attempt to see if the staphylococcus produced a toxin.

The risk of toxic shock syndrome may be reduced by using tampons intermittently rather than continuously during a menstrual period. The condition should be managed by intensive fluid replacement, and antistaphylococcal antibiotics should be administered after appropriate cultures have been obtained. It is recommended that women who have had an episode of toxic shock syndrome should not use tampons for several menstrual cycles.

I thank Dr H Pullen for permission to report this case admitted under his care.

1 Anon. Toxic shock and tampons. Br Med f 1980;281:1161-2.

2 Todd J, Fishaut M, Kapral F, Welch T. Toxic-shock syndrome associated with phage-group-1 staphylococci. Lancet 1978;ii:116-8.

${ }^{3}$ Schrock CG, Disease alert. F $A M A$ 1980;243:1231.

${ }^{4}$ United States Department of Health and Human Services/Public Health Service. Follow-up on toxic-shock syndrome-United States. Morbid Mortality Weekly Report 1980;29:441-5.

(Accepted 4 November 1980)

Department of Infectious Diseases, Seacroft Hospital, Leeds LS14 6UH

PAUL HOLT, MRCP, senior registrar

\section{Theophylline and depression}

The cerebral stimulant effects of the bronchodilator theophylline are well known. Nevertheless, we have recently seen two cases of severe depression with this drug, a paradoxical and unreported reaction.

\section{Case reports}

(1) A 19-year-old asthmatic girl (weight $48 \mathrm{~kg}$ ) had theophylline $225 \mathrm{mg}$ twice daily added to her standard regimen of inhaled salbutamol and beclomethasone because of increasing bronchospasm. Over a period of one month she unaccountably became depressed and irritable having previously had a stable personality. Her symptoms disappeared promptly on withdrawal of theophylline alone, but its reintroduction two weeks later for an exacerbation of bronchospasm precipitated a further episode of profound depression. Stopping the drug again relieved the symptoms.

(2) An 11-year-old asthmatic girl (weight $31 \mathrm{~kg}$ ) with eczema and dyslexia was admitted to hospital. Since treatment with salbutamol, beclomethasone, and disodium cromoglycate inhalation was insufficient she was started on theophylline $225 \mathrm{mg}$ twice daily. She was discharged one week later. Shortly afterwards she became acutely depressed, had frequent episodes of crying and on one occasion admitted to "wanting to take all the tablets and finish everything." Again, no exogenous cause could be identified and after theophylline was stopped her depression disappeared immediately.

\section{Comment}

These two cases suggest a paradoxical depressive reaction induced by theophylline. The absence of premorbid depression, the temporal relationship of the onset of symptoms to starting theophylline, their prompt disappearance when it was stopped, and (in the first patient) their return with the reintroduction of theophylline suggest a causeand-effect relationship. Paradoxic ${ }^{-1}$ reactions to central nervous depressants are well known and are attributed to selective depression of inhibitory neuronal systems or initial transient release of excitatory transmitters, ${ }^{1}$ but we found only one allusion to stimulant-induced depression. This was an authoritative but unreferenced statement that the "CNS excitation produced by large amounts of caffeine is followed by depression."' There is considerable experimental evidence that xanthines promote the release of catecholamines from the adrenal medulla ${ }^{3}$ and peripheral adrenergic nerve endings. ${ }^{4}$ The occurrence of such neurotransmitter depletion in the central nervous system of susceptible individuals could explain the theophylline-induced depression in our patients. Neural catecholamine exhaustion is the basis of Jacobsen's widely accepted hypothesis ${ }^{5}$ on the aetiology of depression.

The paradoxical reaction seen in our two patients is obviously uncommon, but clinicians should be aware of it as a possibility in unexpected depression in a patient taking theophylline.

${ }^{1}$ Di Mascio A. The benzodiazepines. New York: Raven Press, 1973:433-40.

2 Goodman LS, Gilman A. In: Ritchie JM, ed. The pharmacological basis of therapeutics, 5th ed. London: Macmillan, 1975:368.

${ }^{3}$ Poisner AM. Direct stimulant effect of aminophylline on catecholamine release from the adrenal medulla. Biochem Pharmacol 1973;22:469-76.

4 Westfall DP, Fleming WW. Sensitivity changes in the dog heart to norepinephrine, calcium and aminophylline resulting from pre-treatment with reserpine. F Pharmacol Exp Ther 1978;159:98-105.

5 Jacobsen E. The theoretical basis of the chemotherapy of depression. In Davies EB, ed. Proceedings of the symposium held at Cambridge 22-26t September 1959. London: Cambridge University Press, 1964:208-13.

(Accepted 24 September 1980)

Medical Professorial Unit, University College Dublin, St Vincent's

Hospital, Dublin 4

MICHAEL B MURPHY, MB, MRCPI, medical registrar

AILEEN DILLON, MB, medical intern

M X FITZGERALD, MD, FRCP, professor of medicine

\section{Controlled trial of bladder drill for detrusor instability}

We report a controlled trial of inpatient bladder drill for detrusor instability. Sixty women participated and results were assessed both subjectively and by repeat urodynamic studies.

\section{Patients, methods and results}

Sixty women aged 27-79 with urinary incontinence due to idiopathic detrusor instability diagnosed by pressure-flow studies entered a clinical trial of bladder drill. None was taking a drug known to affect urinary tract function or had coexisting genuine stress incontinence. Cystoscopy and urethral dilatation were performed under general anaesthesia to exclude local disease and measure bladder capacity. Each patient was then allocated at random either to inpatient bladder drill or to serve as a control; controls

Symptoms of patients before and six months after treatment

\begin{tabular}{lcccccc}
\hline \multirow{2}{*}{ Symptoms } & \multicolumn{2}{c}{ Bladder-drill group $(\mathbf{n}=30)$} & & \multicolumn{2}{c}{ Control group $(\mathbf{n}=30)$} \\
\cline { 2 - 3 } \cline { 6 - 7 } & \multicolumn{2}{c}{ Before } & After & & Before & After \\
\hline Diurnal frequency & $\cdots$ & 30 & 5 & & 30 & 23 \\
Nocturnal frequency & $\cdots$ & 27 & 3 & & 25 & 20 \\
Urgency & $\cdots$ & 30 & 3 & & 30 & 23 \\
Urge incontinence & $\cdots$ & 30 & 3 & & 30 & 23 \\
Stress incontinence & $\cdots$ & 21 & 3 & & 20 & 16
\end{tabular}

were advised that they should now be able to hold their urine for four hours be continent, and allowed home. All patients were reassessed clinically and by repeat pressure-flow studies after three and six months.

We use the following bladder drill in our unit. (1) The rationale is explained. (2) The patient is instructed to pass urine at specific intervals 